\title{
Urination and defecation by group-housed dairy calves
}

\author{
Alison Vaughan, ${ }^{*}{ }^{1}$ Anne Marie de Passillé, ${ }^{*}$ Joseph Stookey, $\dagger$ and Jeffrey Rushen* \\ ${ }^{*}$ Pacific Agri-Food Research Centre, Agriculture and Agri-Food Canada, PO Box 1000, Agassiz, BC, V0M 1A0 Canada \\ †Department of Large Animal Clinical Sciences, Western College of Veterinary Medicine, University of Saskatchewan, Saskatoon, Saskatchewan, \\ S7N 5B4 Canada
}

\begin{abstract}
A better understanding of when and where grouphoused calves are most likely to defecate or urinate might permit improved housing design or more efficient use of cleaning routines. However, this is the first study to address the urination and defecation habits of calves. The primary aims of this study were to report the daily frequency of calves' urination and defecation and determine when and where group-housed dairy calves defecate and urinate most frequently. We were also interested to see if incidence of urination and defecation changed with increasing age and the change in diet at weaning. We observed 36 female Holstein calves, housed in groups of 9, and fed milk, grain, and hay from automated feeders. For the purposes of another experiment, these calves were assigned to 1 of 3 experimental treatments relating to age at start of weaning and milk allowance: low milk allowance and early weaning $(6 \mathrm{~L} / \mathrm{d}, 42 \mathrm{~d})$, high milk allowance and early weaning (12 L/d, $42 \mathrm{~d}$ ), and high milk allowance and late weaning $(12 \mathrm{~L} / \mathrm{d}, 84 \mathrm{~d})$ The occurrence of defecations and urinations was determined by continuous observation of video recordings taken over $72 \mathrm{~h}$ at 2 age periods (age, mean $\pm \mathrm{SD}$; period $1=32.0 \pm 11.13 \mathrm{~d}$ and period $2=61 \pm 11.29 \mathrm{~d})$. Due to the treatments, weaned and unweaned calves were observed in each period (period 1: 34 unweaned and 2 weaned calves; period 2: 16 unweaned and 20 weaned calves). Large differences were found between calves in mean daily frequency of total urinations and defecations across a $3-\mathrm{d}$ period $($ mean $=17.56 \pm 5.07 / \mathrm{d}$, range $=4.33$ to 28.67$)$. Differences between individual calves did not change significantly over time, provided calves remained unweaned. Two days of observation was sufficient to give a reliable estimate of daily urination and defecation frequency. Frequency of urination and defecations was higher in calves postweaning. Higher age and visits to the milk feeder were associated with a higher frequency of urinations and defecations preweaning. After wean-
\end{abstract}

Received October 2, 2013.

Accepted March 15, 2014.

${ }^{1}$ Corresponding author: alison.vaughan@usask.ca ing, frequency of eliminations increased with increasing visits to the water feeder. An effect of time of day was observed, with significantly more events during daylight hours $(0600-1800 \mathrm{~h})$ in comparison to night (1800-0600 h). Before weaning, calves urinated and defecated significantly more on slatted flooring and sawdust-bedded areas than within the feeder (daily mean $\pm \mathrm{SD}=6.96$ $\pm 3.15,6.49 \pm 3.90$, and $4.10 \pm 2.67$ for slatted floor, bedded floor, and feeder areas, respectively). Frequency of eliminations in feeders and slatted, but not sawdustbedded, areas was higher in calves postweaning. Calves urinate and defecate more frequently during daylight hours when they are more active. Slatted flooring around feeders is useful to reduce soiling of bedded areas, particularly as calves increase in age.

Key words: dairy calf, urination, defecation

\section{INTRODUCTION}

Interest is increasing in housing unweaned dairy calves in groups, which has the potential to reduce the labor associated with both cleaning and feeding (Kung et al., 1997). Accumulation of the feces and urine of grouphoused calves can increase the potential for transmission of disease between conspecifics and also pose a risk to human health (Pell, 1997). Furthermore, the release of volatile ammonia, occurring when urea (found in urine) comes into contact with urease (found in feces), is related to several environmental problems (Moreira and Satter, 2006; Sheppard et al., 2007). Despite the importance of elimination behaviors, little is known of the factors that influence defecation or urination by cattle and, to our knowledge, no studies have addressed the urination and defecation habits of calves. A better understanding of when and where group-housed calves defecate and urinate might permit improved housing design, reduced soiling of bedding, or more efficient use of cleaning routines.

Some studies have suggested a link between diet and frequency of defecations, but this link has not yet been supported by evidence (Hirata et al., 2011; Villettaz Robichaud et al., 2011). The majority of studies have examined urination and defecation in adult dairy cattle, which are typically subject to intensive man- 
agement practices with relatively rigid daily routines. Although Villettaz Robichaud et al. (2011) found no diurnal rhythm in urination and defecation behaviors nor any correlation between the frequency of urination and defecation in each hour of the day and feeding activity, Aland et al. (2002) found that most defecation in adult cows occurred during the hours when the animals were most active; that is, during milking and feeding. Group-housed calves fed milk and grain ad libitum via automated feeders are not subject to an artificially imposed time budget and it would be interesting to see if a similar pattern of activity in elimination behaviors is seen.

Some studies have recorded the locations where cows were most likely to defecate or urinate (Whistance et al., 2007; Oudshoorn et al., 2008; Villettaz Robichaud et al., 2011). Cattle permitted limited access to pasture were found to defecate and urinate over their entire grazing surface, without accumulation in specific hot spots (Oudshoorn et al., 2008). In contrast, in freestall housing, urination and defecation was concentrated in feed alleys and alleyways behind the stalls, which may reflect how much time the cows spent in that area (Whistance et al., 2007; Villettaz Robichaud et al., 2011). The aims of the current study were to determine when and where group-housed dairy calves defecate and urinate most frequently, and to look at the relationship between the frequency of defecation and urination by calves, pre- and postweaning, and in relation to age, feed intake, feeder visits, weaning, and time of day.

\section{MATERIALS AND METHODS}

Thirty-six female Holstein calves [birth weight (mean $\pm \mathrm{SD})=43.12 \pm 4.74 \mathrm{~kg}]$ were removed from their dams and fed $4 \mathrm{~L}$ of high-quality colostrum within 6 $\mathrm{h}$ of birth and housed individually in concrete-floored pens $(1.22 \times 2.44 \mathrm{~m})$ with sawdust bedding. Within the first $24 \mathrm{~h}$ of age, calves were weighed and an identification tag fitted with a transponder was attached to the left ear. While individually housed they received $12 \mathrm{~L}$ of pasteurized whole milk per day (i.e., ad libitum) in 2 meals (approximately 0800 and $1500 \mathrm{~h}$ ) via an artificial teat attached to the pen wall.

At 4 to $5 \mathrm{~d}$ of age $($ mean $=4.5 \mathrm{~d})$, calves were added to group pens until 9 calves were housed in each pen, with a maximum age range of $30 \mathrm{~d}$ within each group. Each group of 9 calves was housed in a pen with a 4.74$\times 2.48$-m plastic-coated, expanded metal floor at the front of the pen and a 4.74- $\times$ 4.64-m concrete-based area, bedded with wood shavings, at the rear (Figure 1). Fresh bedding was added to each pen once per week.

The pens contained 1 automated milk feeder and 1 automated grain feeder (DeLaval CF 1000 CS Combi,
Tumba, Sweden) as well as 1 automated hay feeder and 1 automated drinker (Insentec, Marknesse, the Netherlands). The automated milk feeder, situated at the front of each group pen, provided calves with filtered and pasteurized waste milk via an artificial teat. Portions of milk became available from the feeder throughout the day and could either be consumed as each new portion became available or accumulated across several hours (e.g., for an allowance of $12 \mathrm{~L} / \mathrm{d}$, an additional $0.5 \mathrm{~L}$ would become available every hour, up to a maximum of $6 \mathrm{~L}$ in 1 visit to the feeder). Grain feeders dispensed commercial calf starter mix $(17.4 \%$ protein, $6.37 \%$ fiber, and $4.38 \%$ fat; Unifeed Ltd., Chilliwack, Canada) in $20-\mathrm{g}$ portions, at a maximum rate of $9 \mathrm{~kg} / \mathrm{d}$ (i.e., ad libitum). Grass hay ( $\mathrm{DM}=90.8 \%, \mathrm{CP}=15.1 \%, \mathrm{NDF}$ $=51.1 \%$, and $\mathrm{ADF}=33.6 \%)$ and water were freely available. For the purposes of another experiment (de Passillé et al., 2011), calves entering the group pen were assigned to 1 of 3 experimental treatments relating to age at start of weaning and milk allowance: low milk allowance and early weaning (6 L/d, $42 \mathrm{~d})$, high milk allowance and early weaning (12 L/d, $42 \mathrm{~d})$, and high milk allowance and late weaning $(12 \mathrm{~L} / \mathrm{d}, 84 \mathrm{~d})$. Three calves from each treatment were in each group pen.

DeLaval feeders measured the daily individual milk and grain intakes for each calf using the volume of feed dispensed. Both grain and milk feeders recorded the number and duration of visits. The hay feeders and drinkers were equipped with hydraulic scales, which allowed for the number of visits and consumption of hay and water to be measured. Visits to feeders without consumption of feed were excluded from analyses. Data from milk and grain feeders were recorded and stored by Kalbmanager and Win_Institute programs (Foerster-Technik, Engen, Germany). Water and hay consumption was recorded by Insentec RIC - System IV TIRIS Identification Roughage/Water Version 11 UH7802 (Insentec).

\section{Behavioral Observations}

Three overhead video cameras (WVBP 334, Panasonic, Oskaka, Japan) were mounted on the ceiling above each pen, and an additional camera was mounted so that the entire pen could be viewed and recorded continuously at normal speed using digital video recorders (Genetec Inc., Saint-Laurent, QC, Canada). The videos were read at $4 \times$ normal speed. To validate video identification of elimination behaviors, $4 \mathrm{~h}$ of direct observation were compared with overhead video.

The 4 groups of calves were randomly allocated between 3 observers. Each group of calves was watched by a single trained observer. All observers completed training before beginning data collection using a sam- 


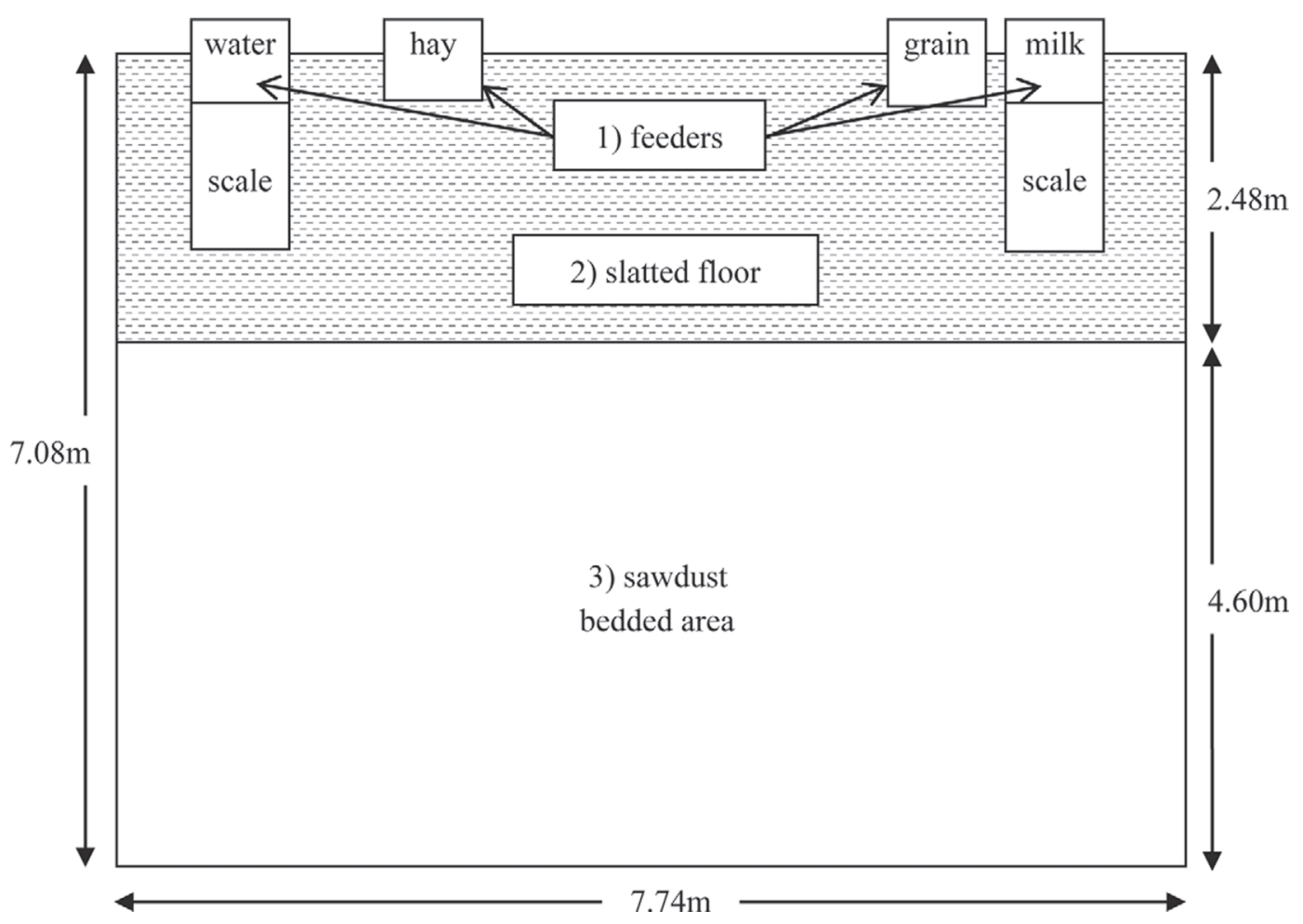

Figure 1. Layout of experimental calf pen showing the 3 locations: (1) feeders, (2) slatted floor, and (3) sawdust-bedded area.

ple video. Following 3 repetitions of the sample video, inter- and intraobserver reliability were calculated using the results. Experimental data collection only commenced once the reliability was of a satisfactory level $\left(\mathrm{r}_{\text {Pearson }}>0.8\right)$. This process was repeated, using the same footage, halfway through watching each group to ensure data collection remained consistent.

To obtain a range of ages and milk allowances, each group of calves was watched at 2 periods, 4 wk apart. To ensure data reflected a good representation of the calves' behavior, 3 consecutive days $(3 \times 24 \mathrm{~h})$ were selected for each observation period, with a total of $6 \mathrm{~d}$ per calf. Due to the weaning treatments $(\mathrm{n}=12$ calves per treatment), weaning occurred at different ages, and thus both weaned and unweaned calves were observed at each observation period (observation period 1: 34 unweaned and 2 weaned calves; observation period 2 : 16 unweaned and 20 weaned calves). On each observation day all the calves within a group pen were watched and the type (urination, defecation, or unidentified), time (to the nearest second), and location of each elimination event was recorded for each calf. The location of the calf during defecation and urination was recorded using 3 locations, as shown in Figure 1. A defecation or urination event was considered to have occurred in the feeder if the calf's head was within the feeder stall. If the calf was moving, the location where the first drop of urine or feces fell was recorded. The position of calves (e.g., standing or lying) was also noted.

Eliminations were identified using the characteristic posture adopted by calves (defecation: tail lifted and back slightly arched; urination: tail lifted, back arched, hind legs placed forward and apart) or evidence of either manure (new feces on the floor) or urine (spray of urine on the floor; Villettaz Robichaud et al., 2011). In some incidences it was not possible to distinguish the type of elimination event from the video and these events that could not be confidently categorized were marked as "unidentified." To determine whether urinations and defecations were equally likely to be unidentified, a sample of $4 \mathrm{~h}$ of direct and video observation of urinations and defecations were compared.

\section{Organization of Data and Analysis}

Data were analyzed using SAS software (SAS Institute, 2011). Data was reported for individual calves within group pens. For each calf, the mean daily frequencies of defecation, urination, unidentified events, and total events were calculated for each 3 -d observation period, and the distributions of these data were described using the minimum, 25th quartile, median, 75th quartile, and maximum. As it was not possible to distinguish between urination and defecation in $28 \%$ 
of the events, unidentified events were combined with urinations and defecations to give total eliminations for all subsequent analysis

No difference was observed between weaning treatments in the frequency of eliminations (student $t$-test: $t$ $=0.22 ; P=0.83$ ) so treatments were pooled for all subsequent analysis. The quantities of milk, starter, hay, and water consumed by each calf were automatically recorded by feeders, but a full data set was available for only 33 calves. As calves were weaned at different ages due to the weaning treatments, we had unequal numbers of pre- and postweaning data within each observation period. Data were available for 31 preweaning calves (age range: 17-58 d) in observation period 1, for 20 postweaning calves in observation period 2 (age range: $56-82 \mathrm{~d}$ ), and both pre- and postweaning data were available for 18 of the calves.

Pearson correlation was calculated between the mean daily frequency of urinations, defecations, and unidentified events (pooled) as well as age, milk, grain, hay and water intakes, and frequency of visits to feeders across each 3 -d observation period for pre- $(\mathrm{n}=31)$ and postweaning $(\mathrm{n}=20)$ periods. Stepwise regression analysis was conducted to determine which of the independent variables (age, milk, grain, hay and water intakes, and feeder visits) had the greatest influence on frequency of eliminations, pre- and postweaning. Paired $t$-tests were used to test for differences in frequency of events between night and day and frequency of events between pre- and postweaning. Differences in the frequency of eliminations between the 3 different locations were tested using a one-way ANOVA with pairwise comparisons of mean values using Tukey's test.

To determine how many days of observation are required to give a reliable estimate of daily elimination frequency of calves, 1-, 2-, and 3-d means were compared using Pearson correlation within and between each period. Pearson correlation was also used to compare $3-\mathrm{d}$ averages between observation periods; calves that were preweaning in both observation periods $(\mathrm{n}=16)$ and calves that weaned between observation periods $(\mathrm{n}=$ 18) were considered separately. The frequency distribution of eliminations across $24 \mathrm{~h}$ was compared between pre- and postweaning using Pearson correlation.

\section{RESULTS}

Large differences were found between calves in the frequency of elimination events (Table 1). Comparison between the $4 \mathrm{~h}$ of direct and video observations revealed that defecations and urinations were not equally likely to be uncategorized, with the latter accounting for almost two-thirds of unidentified events. Differences in the frequency of eliminations between individuals were relatively consistent between the 2 observation periods for calves that had not begun the weaning process $(\mathrm{n}=16, \mathrm{r}=0.84, P<0.001)$. For calves that were weaned between the 2 observation periods, however, no significant correlation in the frequency of elimination was found $(\mathrm{n}=18, \mathrm{r}=0.29, P=0.24)$. Calves were never observed to urinate or defecate while lying down.

Calves had significantly more elimination events after weaning (paired student $t$-test; $\mathrm{n}=18, t=4.59, P$ $<0.001$; mean $\pm \mathrm{SD}$, preweaning $=17.33 \pm 2.16$ and postweaning $=21.33 \pm 3.83$ ); consequently, pre- and postweaning calves were considered separately in the subsequent analysis. Before weaning, a significant low correlation was found between frequency of elimination events and age, and a tendency toward a positive correlation with visits to the water and milk feeders and overall feeder visits was found (Table 2). Multiple linear regression of preweaning data found that age and frequency of visits to the milk feeder were the main factors explaining variation in frequency of eliminations (n $=31$; age: $F=8.35, P=0.01$; visits to milk feeder: $F=5.06, P=0.03)$. After weaning, eliminations were correlated with frequency of visits to the water feeder, and a nonsignificant trend was found for eliminations to increase with increasing water intake (Table 2). The results of regression analysis, for postweaning data, in-

Table 1. Daily frequency of elimination events averaged across the 2 observation periods

\begin{tabular}{|c|c|c|c|c|c|c|}
\hline Item & Event type & Minimum & 25th percentile & Median & 75th percentile & Maximum \\
\hline \multirow{2}{*}{ All observations $(\mathrm{n}=36)$} & Urination & 1.33 & 5.33 & 6.33 & 8.50 & 13.67 \\
\hline & Unidentified & 1.67 & 3.67 & 4.33 & 5.92 & 12.33 \\
\hline \multirow{3}{*}{ Preweaning $(\mathrm{n}=34)$} & Defecation & 0.33 & 3.33 & 4.50 & 5.67 & 9 \\
\hline & Urination & 1.33 & 5.33 & 6.33 & 7.67 & 12.67 \\
\hline & Unidentified & 1.67 & 3.33 & 4.33 & 5.33 & 12.33 \\
\hline \multirow{3}{*}{ Postweaning $(\mathrm{n}=20)$} & Urination & 2.67 & 4.83 & 6.50 & 9.17 & 13.67 \\
\hline & Unidentified & 2.67 & 4.00 & 4.83 & 7.67 & 12.00 \\
\hline & Total eliminations & 14.67 & 18.00 & 21.83 & 23.33 & 28.67 \\
\hline
\end{tabular}


Table 2. Pearson correlations between frequency of urinations and defecations (pooled) and age, grain, hay, water and milk intake, and feeder visits across $36 \mathrm{~h}$ for pre- and postweaning observations ( $P$-values in parentheses)

\begin{tabular}{lcc}
\hline & \multicolumn{2}{c}{$\begin{array}{c}\text { Mean frequency of urination and } \\
\text { defecation (across } 36 \mathrm{~h})\end{array}$} \\
\cline { 2 - 3 } Item & $\begin{array}{c}\text { Preweaning } \\
(\mathrm{n}=31)\end{array}$ & $\begin{array}{c}\text { Postweaning } \\
(\mathrm{n}=20)\end{array}$ \\
\hline Age & $0.49(0.01)$ & $0.24(0.32)$ \\
All feeder visits & $0.33(0.07)$ & $0.20(0.41)$ \\
Grain intake & $0.05(0.78)$ & $0.36(0.12)$ \\
Visits to grain feeder & $0.13(0.48)$ & $0.03(0.90)$ \\
Hay intake & $0.02(0.90)$ & $-0.08(0.74)$ \\
Visits to hay feeder & $0.05(0.78)$ & $-0.08(0.73)$ \\
Water intake & $0.30(0.10)$ & $0.43(0.06)$ \\
Visits to drinker & $0.35(0.05)$ & $0.45(0.05)$ \\
Milk intake & $0.24(0.19)$ & $\mathrm{NA}{ }^{1}$ \\
Visits to milk feeder & $0.32(0.08)$ & $\mathrm{NA}$ \\
\hline
\end{tabular}

${ }^{1} \mathrm{NA}=$ not applicable.

dicated that frequency of visits to the water feeder was the only variable accounting for variation in frequency of eliminations (n $=20, F=4.53, P=0.05)$.

We found some evidence of diurnal rhythms in the frequency of elimination events (Figure 2). Significantly more events occurred during daylight hours (0700-1800 $\mathrm{h})$ in comparison to night $(1900-0600 \mathrm{~h}$; student $t$-test: $\mathrm{n}=36, t=22.65, P<0.001$; mean: 10.73 and 1.79 events for day and night, respectively). The fewest events occurred between 0400 and $0500 \mathrm{~h}$, and frequency of eliminations sharply increased at $0700 \mathrm{~h}$, peaking at $0800 \mathrm{~h}$. The frequency distribution of eliminations across $24 \mathrm{~h}$ did not change significantly after weaning $(\mathrm{r}=0.69, P<0.001)$. Frequency of calves' eliminations per hour and the frequency of visits to the feeders per hour were highly correlated (Figure $2 ; \mathrm{r}=0.86, P<$ $0.001)$.

No difference in the frequency of elimination events occurring on the slatted floor and sawdust-bedded areas was observed, although significantly less events occurred within feeders than other areas (one-way ANOVA; n $=36, F=7.88, P=0.001$; mean frequency $\pm \mathrm{SD}=6.96 \pm 3.15,6.49 \pm 3.90$, and $4.10 \pm 2.67$ for slatted floor, bedded floor, and feeder areas, respectively). After weaning, a significant increase was observed in the frequency of urinations and defecations occurring in feeders and the slatted area of the group pen (paired $t$-test: $\mathrm{n}=18, t=4.12, P=0.01,2.69$, and 0.02 , respectively), but no significant change in the frequency of urinations and defecations on the sawdust-
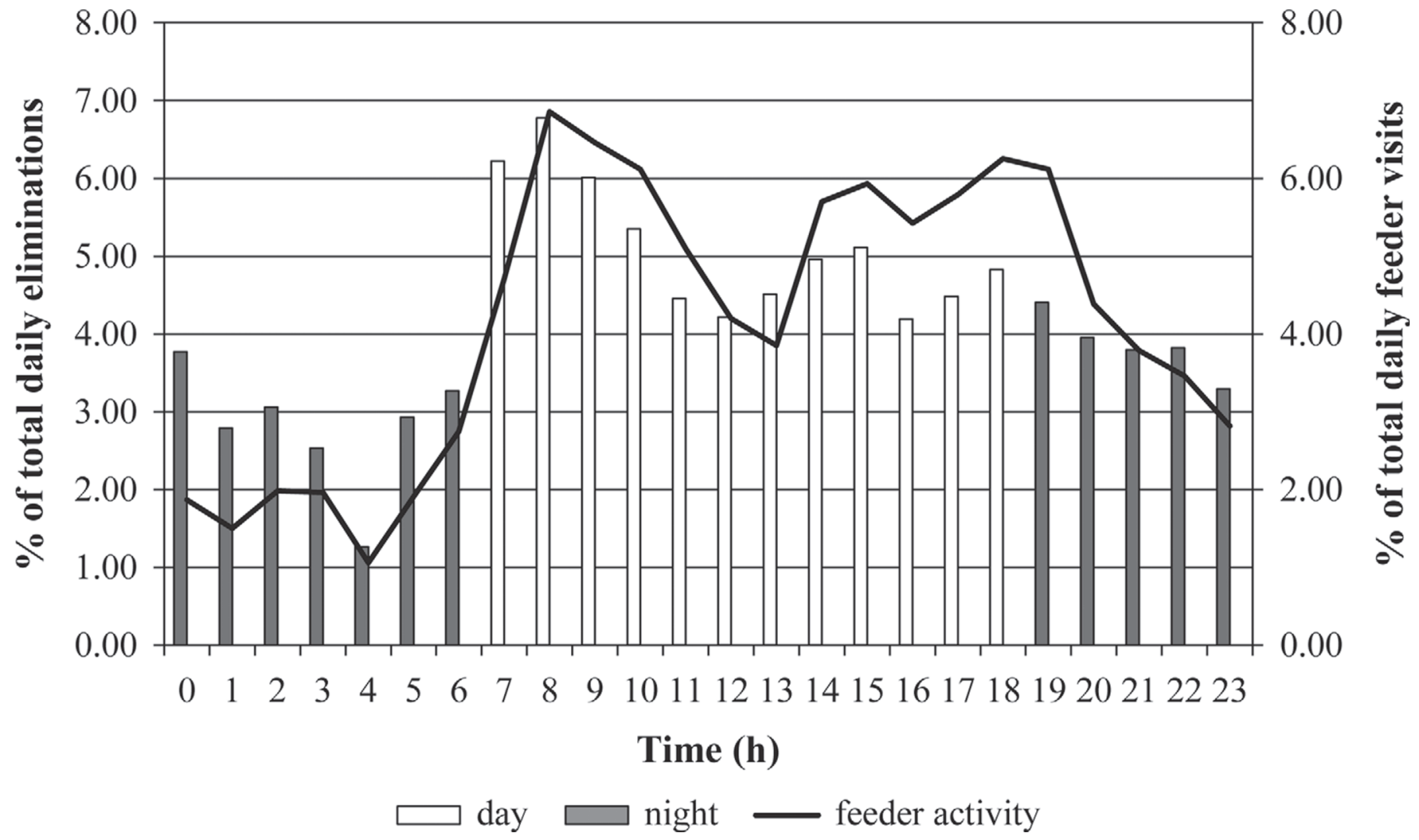

Figure 2. Percentage of the daily elimination events (urination and defecation pooled) and percentage of total daily visits to the feeders occurring at each hour of the day. Data averaged across $6 \mathrm{~d}, \mathrm{n}=36$. 


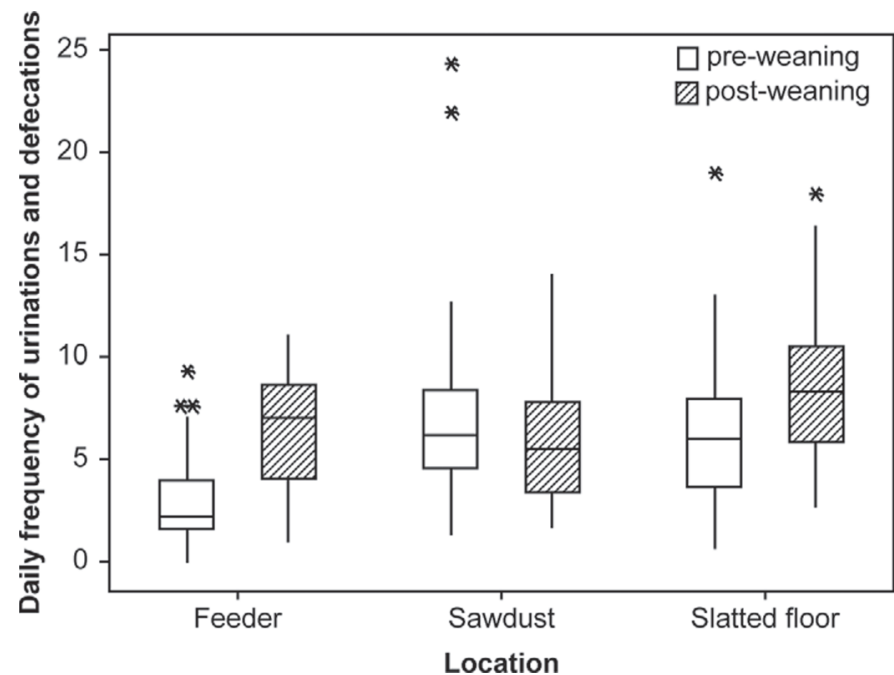

Figure 3. Daily frequency of urination and defecation occurring in each location within the pen, pre- and postweaning $(n=18)$. The box plot shows the median and 25th and 75 th percentile of daily frequency of eliminations (urinations and defecations pooled), lines show minimum and maximum values, asterisks (*) show outliers.

bedded area (paired $t$-test: $\mathrm{n}=18, t=0.51, P=0.61$; Figure 3).

At each period, a low to moderate correlation was noted between calves' frequency of elimination on individual days. Moderate to strong correlations were observed between 1- and 3-d averages (preweaning: $\mathrm{n}=$ $34, \mathrm{r}=0.86, P<0.001$; postweaning: $\mathrm{n}=20, \mathrm{r}=0.77$, $P<0.001)$. Two-day averages, however, were highly correlated both with individual day (preweaning: $\mathrm{n}=$ $34, \mathrm{r}=0.92, P<0.001$; postweaning: $\mathrm{n}=20, \mathrm{r}=0.82$, $P<0.001$ ) and 3-d averages (preweaning: $\mathrm{n}=34, \mathrm{r}=$ 0.97, $P<0.001$; postweaning: $\mathrm{n}=20, \mathrm{r}=0.95, P<$ $0.001)$.

\section{DISCUSSION}

Large differences were observed in the frequency of eliminations between individual calves, something which has also been noted in studies of adult cattle (Villettaz Robichaud et al., 2011). Day-to-day variation was observed in the frequency of individual calves' eliminations; however, observing 2 consecutive days was sufficient to give an accurate estimation of daily frequency. Interestingly, the frequency of eliminations was highly correlated between the 2 observation periods, 1 mo apart, but only for calves that were not weaned between these periods.

The frequency of urination and defecation increased significantly after weaning. Prior to weaning, age and frequency of visits to the milk feeder were the main factors accounting for the variation in frequency of eliminations between calves. After weaning, frequency of eliminations was positively correlated with visits to the water feeder. Interestingly, frequency of visits to the feeder appeared to be more important than amount of feed consumed. As it was not possible to confidently categorize all incidences of urination and defecation, it is not clear whether the increase in daily eliminations represents an increase in urinations or defecations.

Even taking into account uncategorized eliminations (the greater proportion of unidentified events were found to be urinations when video was compared with direct observations), daily frequency of observed defecations was approximately half that reported for cows kept in tiestall, freestall, and straw-pen barns (Aland et al., 2002; Whistance et al., 2007; Villettaz Robichaud et al., 2011). Given the shift from a mainly liquid to solid feed occurring at weaning, it seems intuitive that an increase in the frequency of defecations would account for the observed increase in daily eliminations postweaning. However, both before and after weaning, frequency of eliminations was correlated with visits to milk and water feeders and no correlation was found between either solid feed intake or visits to hay or grain feeders.

A link between feed intake and frequency of defecation has been proposed by other studies (Hirata et al., 2011). However, the variation in the frequency of defecation and urination was not related to variation in feed and water intake in Villettaz Robichaud et al. (2011), and it may be that the increase in frequency of events owes more to increasing age. Aland et al. (2002) reported possible age effects on urination and defecation behavior, with cows defecating but not urinating more frequently than heifers. In the current study, older calves had a higher frequency of eliminations before weaning, but this relationship was not found in postweaning observations. The age range of calves observed before weaning was greater than that of those observed postweaning, and it may be that an age effect would also be apparent after weaning had the variation in age been greater between observed calves.

We did not measure the volume of urine and feces excreted in the current study, and it may be that diet had an effect on the volume of urine and feces excreted at each episode. To our knowledge, although attempts have been made to measure fecal output or defecation (Hirata et al., 2011), no study has validated frequency of urinations and defecations as a measure of volume of urine and feces excreted. It may be that differences in volume or elimination events account for some of the large individual variation reported between adult cattle in Villettaz Robichaud et al. (2011). Nevertheless, frequency of eliminations is likely a more important measure in terms of cleanliness, as a calf that defecates 
frequently may be more likely to spread manure around than a calf that defecates larger volumes in fewer locations.

We found a significant difference in the frequency of eliminations between day and night, with significantly more events during 0600 to $1800 \mathrm{~h}$, when calves have been reported to be more active (Hänninen et al., 2005). In the current study, the frequency of urinations and defecations per hour was strongly correlated with feeding behavior (as estimated by frequency of feeder visits per hour). The diurnal pattern was correlated between pre- and postweaning periods and did not appear to be influenced by age or total daily frequency of eliminations. The proportion of elimination events occurring per hour bears a striking similarity to that reported both for cattle on pasture (Hirata et al., 2011) and in tiestalls (Aland et al., 2002). In contrast, Villettaz Robichaud et al. (2011) reported no diurnal pattern in either defecation or urination behaviors, although a large proportion of defecations and eliminations occurred directly after cows changed from lying to standing (also reported in Aland et al., 2002), which supports the suggestion that change in activity from resting to active behaviors may lead to an increase in the frequency of events.

No significant difference was observed between the mean daily frequency of events occurring on the sawdust-bedded area and the slatted area around the feeders. The frequency of elimination events around the slatted floor and feeders, but not the sawdust-bedded area, increased significantly with increasing age. This may reflect calves spending more time in and around the feeders, particularly directly after weaning, when visits to the milk feeder increase dramatically as calves unsuccessfully attempt to access milk (de Passillé et al., 2011). Additionally, this may reflect a change in the activity budget and, as a result, time spent in different areas of the pen, as time spent resting decreases with increasing age, with a particular drop around weaning (Hänninen et al., 2005). Using slatted flooring around feeders has the potential to keep group pens cleaner, particularly as calves become more active with increasing age and during weaning.

\section{ACKNOWLEDGMENTS}

We thank Gosia Zdanowicz and Jean-Philippe Parent of the Ethology Laboratory at the Pacific Agriculture and Agri-Food Research Centre (Agassiz, BC, Canada) and the barn staff of the UBC Dairy Educational and Research Center (Agassiz, BC, Canada) for their help. Particular thanks go to Louis-George Esquilat and Lucia de Simone (both from Agriculture and Agri-Food Canada) for sharing the burden of video watching. Funding was received from the Natural Sciences and Engineering Research Council of Canada (Ottawa, ON, Canada).

\section{REFERENCES}

Aland, A., L. Lidfors, and I. Ekesbo. 2002. Diurnal distribution of dairy cow defecation and urination. Appl. Anim. Behav. Sci. 78:43-54.

de Passillé, A. M., T. F. Borderas, and J. Rushen. 2011. Weaning age of calves fed a high milk allowance by automated feeders: Effects on feed, water, and energy intake, behavioral signs of hunger, and weight gains. J. Dairy Sci. 94:1401-1408.

Hänninen, L., A. M. de Passillé, and J. Rushen. 2005. The effect of flooring type and social grouping on the rest and growth of dairy calves. Appl. Anim. Behav. Sci. 91:193-204.

Hirata, M., M. Higashiyama, and N. Hasegawa. 2011. Diurnal pattern of excretion in grazing cattle. Livest. Sci. 142:23-32.

Kung, L. Jr., S. Demarco, L. N. Siebenson, E. Joyner, G. F. Haenlein, and R. M. Morris. 1997. An evaluation of two management systems for rearing calves fed milk replacer. J. Dairy Sci. 80:2529-2533.

Moreira, V. R., and L. D. Satter. 2006. Effect of scraping frequency in a freestall barn on volatile nitrogen loss from dairy manure. J. Dairy Sci. 89:2579-2587.

Oudshoorn, F. W., T. Kristensen, and E. Shahrak. 2008. Dairy cow defecation and urination frequency and spatial distribution in relation to time-limited grazing. Livest. Sci. 113:62-73.

Pell, A. N. 1997. Manure and microbes: Public and animal health problem? J. Dairy Sci. 80:2673-2681.

SAS Institute. 2011. SAS User's Guide. SAS Institute Inc., Cary, NC.

Sheppard, S. C., S. Bittman, J. Tait, S. J. Sommer, and J. Webb. 2007. Sensitivity analysis of alternative model structures for an indicator of ammonia emissions from agriculture. Can. J. Soil Sci. 87:129-139.

Villettaz Robichaud, M., A. M. D. Passillé, D. Pellerin, and J. Rushen. 2011. When and where do dairy cows defecate and urinate? J. Dairy Sci. 94:4889-4896.

Whistance, L. K., D. R. Arney, L. A. Sinclair, and C. J. C. Phillips. 2007. Defecation behaviour of dairy cows housed in straw yards or cubicle systems. Appl. Anim. Behav. Sci. 105:14-25. 